\title{
The Effect of Using the Care Model of "Sensitization" on Medication Adherence in Asthmatic Patients
}

\author{
Mahbobeh Sajadi ${ }^{1}$, Mozhgan Bagheri ${ }^{1}$, Davood Hekmatpou ${ }^{1} \&$ Hamid Borsi $^{2}$ \\ ${ }^{1}$ School of Nursing and Midwifery, Arak University of Medical Sciences, Arak, Iran \\ ${ }^{2}$ Ahvaz University of Medical Sciences, Ahvaz, Iran \\ Correspondence: Mozhgan Bagheri, Master of sciences in Nursing, School of Nursing and Midwifery, Arak \\ University of Medical Sciences, Arak, Iran. E-mail: Mojgan.bagheri@arakmu.ac.ir
}

\author{
Received: November 18, 2015 Accepted: January 25, 2016 Online Published: February 29, 2016 \\ doi:10.5539/gjhs.v8n11p11 \\ URL: http://dx.doi.org/10.5539/gjhs.v8n11p11
}

\begin{abstract}
Introduction: Asthma is a prevalent disease with a multitude of complication. The present research was aimed at investigating the effects of implementing sensitization care model on medication adherence in asthmatic patients.

Methods \& Materials: In this interventional study, 74 subjects were selected using accessibility sampling method and were randomly classified into 2 separate groups, intervention ( 37 subjects) and control group (37 subjects). Data were collected with questionnaire. A month later, the subjects in both groups (control and intervention) completed questionnaire again. The collected data were analyzed using SPSS software, Independent t-test, Paired t-test and Chi-Square.

Results: Data analysis showed that the average age of participants was 41 years (range 21-83). The most and lowest frequencies of marital status in both sexes were $66.2 \%$ married and $33.8 \%$ single, respectively. There was no significant difference before intervention between two groups. However, after the intervention, there was a significant difference between the two groups $(\mathrm{P}=0.0001)$.

Discussion: The results of the present study showed that implementing sensitization care model had a positive effect on medication adherence among asthmatic patients. Therefore, application of this model is recommended to care and treatment asthmatic patients.
\end{abstract}

Keywords: sensitization model, medication adherence, asthma

\section{Introduction}

Asthma is one of the most common chronic diseases that almost 300 million people worldwide are infected (To et al., 2012; Winer, Harrington, Moorman, \& Zahran, 2012). In a report which released in 2003, the prevalence of asthma in the total population was estimated about 5 percent (Axelsson, Ekerljung, \& Lundback, 2015). Asthma is a major problem with a very difficult treatment in most parts of the world and a large number of infected people lose their lives each year. The mortality rate of asthma is increasing in most countries (Winer, Harrington, Moorman, \& Zahran, 2012). It is predicted that 100 million people by 2025, the proportion of patients with asthma in the world to be added (Kasper et al., 2008; To et al., 2012). In Iran and according to the reported statistics by Asthma and Allergy Clinic, 10\% of Iranians suffer from asthma (Ghaffari \& Aarabi, 2013). Many factors increase the complications and problems of patients with asthma that its main reason is the lack of medication adherence (Yang, Chiang, Yao, \& Wang, 2003). These patients are at the risk of severe complications of this disease and worsening of their condition because of the lack of knowledge and science about using medicines and medication adherence (Tran, Coffman, Sumino, \& Cabana, 2014). Studies have shown that non-adherence of medication regimen is a basic and global problem in patients with chronic disease (Tran, Coffman, Sumino \& Cabana, 2014; Tarantino et al., 2010). Non-medication adherence not only reduces the effects of treatment, but also increases the financial burden of the disease (Coban, \& Aydemir, 2014). A study showed that non-adherence to medication regimen, the most important factor causing the failure to control high blood pressure (Schlenk, Bernardo, Organist, Klem, \& Engberg, 2008). In patients with asthma, reducing the severity of the illness is the second leading cause of non-adherence to medication (Dunbar-Jacob \& Mortimer-Stephens, 2001). Poor patients' medication adherence is resulting in lack of access to appropriate 
clinical purposes (Cochrane, Bala, Downs, Mauskopf, \& Ben Joseph, 2000). Some studies have shown that medication adherence is a complex and multifactorial concept associated with his/ her motivations, beliefs and abilities (Clifford, Barber, \& Horne, 2008; Dulmen, Sluijs, Dijk, Ridder, Heerdink, \& Bensing, 2007). Therefore, it seems essential that the necessary training regarding routs of administration, time, self-care and prevention methods of deterioration of their disease is provided (O'Brien, Petrie, \& Raeburn, 1992). Due to the low medication adherence in patients with asthma, it seems that it is better to use the training model that other studies have shown their effectiveness to train patients. One of these models is the care model of sensitization. This model has been used in patients with heart failure in Iran (Hekmatpou, Mohammadi, Ahmadi, \& Arefi, 2009).

\subsection{Objective of the Study}

The present study was conducted to evaluate the effect of care model of sensitization on medication adherence in patients with asthma.

\section{Method \& Materials}

In this interventional study which was conducted in patients with asthma who were visited the Asthma and Allergy Clinic of the teaching hospitals in Ahvaz in 2015 aimed to increase the medical adherence in patients with asthma.

A total of 74 patients were selected by targeted sampling method and then divided randomly into two groups of intervention and control (each group of 37 people).

Inclusion criteria included: age over 18 years old, physician's diagnosis of asthma in patients for at least three months, not having other chronic diseases, the ability to answer the questions and participation in educational sessions. Also, exclusion criteria included: not-wanting to continue the study, death and migration. Patients participated in the study with informed consent and also it was emphasized that they are free to leave the participation in the study at any stage and confidentiality of the study (Polit \& Beck, 2006). Data collecting tool had two parts: the first part contained demographic information (such as age, sex, educational level, disease duration, etc.) and the second part contained the questionnaire of medication adherence. To evaluate the medication adherence, 5-points Likert scale was used $\{($ never $=5),($ rarely $=4)$, (sometimes $=3$ ), (often=2), (always $=1)\}$. A similar of this tool has been used frequently in several countries and its reliability and validity has proven. The scores domain was 10-50. The scores 50 and 30 were considered as medication adherence and non- medication adherence respectively (the scores 10-20, 21-35 and 36-49 are equal to severe non-adherence, average non-adherence and poor non-adherence, respectively). In order to assess the questionnaire reliability of medication adherence, Cronbach's index was used that was 0.73. In order to determining face and content validity of the questionnaire, the experts' comments were used. After allocated the patients into two intervention and control groups, the intervention of care model of sensitization was performed. This model includes 4 stages: cognitive restructuring (patient and family, physician and nurse), 2- the comprehensive program of systematic patient discharge, 3- systematic self-care, 4- creating and sustaining hope among patients. From these 4 stages, two of them were performed in the hospital and two others were followed in patient's home for two month from the start of intervention. This model is stable on the general policy or the strategy of sensitization of treatment team and the patient and his family.

\section{Results}

Data analysis showed that the average age of participants in this research was 41 years (range 21-83). The frequency percentage of women was 45.9 . The most patients were married $(66.2 \%)$. The majority of the participants were under diploma and collegiate ( 40.5 and 36.5 respectively). The most frequency of employment was belonged to housewives $(27 \%)$ and the lowest frequency was related to the soldiers (1\%). More subjects of this research were living in the city $(95.9 \%)$. The majority of patients in this research $(90.5 \%)$ were covered by health insurance. The longest and lowest terms of the disease were 40 years and lower than 1 year, respectively.

Independent $t$-test results showed that the score difference of medication adherence between two intervention and control groups had no significant difference in the start of study $(\mathrm{P}=0.156)$, but after the implementation of the sensitization care model for 2 months, the medication adherence average in intervention group and control group had a significant difference $(\mathrm{P}=0.0001)($ Table 1$)$. 
Table 1. Comparison the mean of medication adherence before and after the intervention between both groups

\begin{tabular}{|c|c|c|c|c|c|}
\hline Variable & & Groups Mea & & T-test* & P-value \\
\hline \multirow{4}{*}{$\begin{array}{l}\text { Medication } \\
\text { adherence }\end{array}$} & \multirow{2}{*}{$\begin{array}{l}\text { Before } \\
\text { Intervention }\end{array}$} & Intervention & $38.8 \pm 6$ & \multirow{2}{*}{1.433} & \multirow{2}{*}{0.0156} \\
\hline & & Control & $37.7 \pm 6.5$ & & \\
\hline & \multirow{2}{*}{$\begin{array}{l}\text { After } \\
\text { Intervention }\end{array}$} & Intervention & $46.2 \pm 2.9$ & \multirow[b]{2}{*}{6.620} & \multirow[b]{2}{*}{0.0001} \\
\hline & & Control & $39.7 \pm 5.7$ & & \\
\hline
\end{tabular}

* Independent t- test.

According to these results, the difference in medication adherence between before and after intervention is significant for the control $(\mathrm{P}=0.001)$ and intervention groups $(\mathrm{P}=0.0001)$. So, the medication adherence in both intervention and control groups has become better. But due to the higher difference of the averages in the intervention group (7.3), it can be concluded that the sensitization care model in the intervention group has been very effectiveness (Table 2).

Table 2. Comparison of medication adherence before and after the intervention in two groups

\begin{tabular}{llllll}
\hline Variable & Groups & & Mean \pm SD & T-test* & P-value \\
\hline \multirow{3}{*}{ Medication adherence } & Intervention & Before & $38.8 \pm 6$ & \multirow{2}{*}{7.892} & 0.001 \\
\cline { 2 - 3 } & & After & $46.2 \pm 2.9$ & & \\
\cline { 2 - 4 } & \multirow{2}{*}{ Control } & Before & $37.7 \pm 6.5$ & \multirow{2}{*}{3.596} & 0.0001 \\
\cline { 2 - 4 } & & After & $39.7 \pm 5.7$ & & \\
\hline
\end{tabular}

* Paired t- test.

\section{Discussion}

This interventional study was performed on 74 patients visiting the Asthma and Allergy Clinic of Imam Khomeini Hospital in Ahvaz city aimed to evaluate the effect of using care model of "sensitization" on the medication adherence in patients with asthma. The results of the present study showed that before intervention, 24 people (15 people in the control group and 9 people in interventional group) and 50 people ( 22 people in the control group and 28 people in interventional group) had average and poor non-medication adherences respectively. In additional, the frequencies of a complete medical adherence and severe non-medical adherence were zero. After implementation of the sensitization care model, the frequency of the average and poor non-medical adherences were 9 people (control group) and 65 people (28 people in the control group and 37 people in the interventional group) respectively, and the frequency of full medical adherence and severe non-medical adherence were zero, too. The research results indicated that there was no relationship or a weak relationship between medical adherence and demographic factors and also clinical variables.

No statistical relationship was observed between the demographic characteristics and medical adherence. Due to the importance of medication adherence, this issue has dragged much attention so that extensive researches on medication adherence in different diseases have been conducted in other parts of the world (Dunbar-Jacob \& Mortimer-Stephens, 2001; Mardby, Akerlind, \& Jorgensen, 2007). The results of the present study showed that there was significant difference in this area. Jimmy, and Jose (2011) state that some of the personal features of patient's can effect on medication adherence.

In this study, the score difference of medication adherence using independent t-test had no significant difference between two intervention (39.8) and control (37.7) groups in the start of study, but after implementation of the sensitization care model for 2 months, the score average of medication adherence had a significant difference in the intervention (46.2) and the control (39.7) groups ( $\mathrm{P}=0.0001)$. Due to the hypothesis of this research, there is a difference between the averages of medication adherence before and after intervention that this difference was under the effect of sensitization model. Bahadoram, et al (2015) in a study on the patients who used Warfarin found that there was a significant relationship between the adherence of using Warfarin and education, life style, patients' jobs, home area and income. They indicated that Warfarin adherence is a multifactorial behavioral process that the roles of education, job, economic and family status of patients are important. So, nurses should 
consider these factors to be able to help the medication adherence improvement of these patients. Hekmatpou, Mohammadi, Ahmadi and Arefi (2009) showed that using the "sensitization model" had a positive effect on the most parameters of the control indices in congestive heart failure such as the average of re-admission rates, body mass index, blood indices and daily activities of life in the patients of interventional group. In general, using the model had caused patients, families and nurse's sensitive and following that preventive of congestive heart failure complications.

Jonasson, Carlsen and Mowinckel (2000) conducted a study regarding the effect of medication adherence of asthma in little children. Measuring the medication adherence in the treatment of children with mild asthma in a long-term study decreases significantly and it emphasized on the importance of monitoring compliance in clinical features. Kardas, Lewek, and Matyjaszczyk (2013) conducted a study regarding the relationship between the control of metabolic diabetes and medication adherence in low-income population. The result of their study showed that medication adherence in diabetes II is strongly related to the control of metabolic diabetes in low-income population. Further effort to facilitate the self-care behaviors of diabetes in low-income population and developing the sensitive and appropriate cultural care are required.

\section{Conclusion}

Results of the present study showed that using the care model of "sensitization" on the medication adherence in patients with asthma has a positive effect. So, it seems that nurses are very effective in implementing of the strategies of adherence improvement because of their presence in all fields of the health care. They can prevent the asthma exacerbations by educating the medications and the correct rout of administration of the inhalation sprays and their complications to the patients. Considering the costs of treatment and due to the efficacy of this native model in order to control and prevent the asthma complication, its use by the care team is recommended.

\section{Acknowledgements}

This article had extracted from a MS dissertation that has been done by the financial support of the School of Nursing and Midwifery, Arak University of Medical Sciences. Therefore, the researchers appreciate from university administrators, authorities of research environment, and all patients who have participated in this project.

\section{Conflict of Interest}

The authors declare that there is no conflict of interests regarding the publication of this paper.

\section{References}

Axelsson, M., Ekerljung, L., \& Lundback, Bo. (2015). The Significance of Asthma Follow-Up Consultations for Adherence to Asthma Medication, Asthma Medication Beliefs, and Asthma Control. Nursing Research and Practice. http://dx.doi.org/10.1155/2015/139070

Bahadoram, S., Naderiravesh. N., Shiri, H., Zohari- Anbohi, S., Khodakarim, S., \& Hasanian- Langroudi, F. (2015). Examining the correlation of adherence to warfarin therapy with demographic characteristic. Journal of Critical Care Nursing, 8(2), 103-8.

Clifford, S., Barber, N., \& Horne, R. (2008). Understanding different beliefs held by adherers, unintentional nonadherers, and intentional nonadherers: Application of the Necessity-Concerns Framework. Journal of Psychosomatic Research, 64(1), 41-6. http://dx.doi.org/10.1016/j.jpsychores.2007.05.004

Coban, H., \& Aydemir, Y. (2014). The relationship between allergy and asthma control, quality of life, and emotional status in patients with asthma: A cross-sectional study. Allergy, Asthma \& Clinical Immunology, 10, 67. http://dx.doi.org/10.1186/s13223-014-0067-4

Cochrane, M. G., Bala, M. V., Downs, K. E., Mauskopf, J., \& Ben Joseph, R. H. (2000). Inhaled corticosteroids for asthma therapy: Patient compliance, devices, and inhalation technique. Chest, 117, 542-550. http://dx.doi.org/10.1378/chest.117.2.542

Dulmen, S. V., Sluijs, E., Dijk, L. V., Ridder, D., Heerdink, R., \& Bensing, J. (2007). Patient adherence to medical treatment: A review of reviews. BMC Health Services Research, 7, 55. http://dx.doi.org/10.1186/1472-6963-7-55

Dunbar-Jacob, J., \& Mortimer-Stephens, M. (2001). Treatment adherence in chronic disease. Journal of Clinical Epidemiology, 54(12), 57-60. http://dx.doi.org/10.1016/S0895-4356(01)00457-7

Ghaffari, J., \& Aarabi, M. (2013). The prevalence of pediatric asthma in the Islamic Republic of Iran: A systematic review and meta-analysis. Journal of Pediatric Review, 1(1), 2-11. 
Hekmatpou, D., Mohammadi, E., Ahmadi, F., \& Arefi, S. H. (2009). Lack of sensitivity to readmission: A grounded theory study for explaining the process of readmitting patients suffering from congestive heart failure. European Journal of Cardiovascular Nursing, 8(5), 355-63. http://dx.doi.org/10.1016/j.ejcnurse.2009.08.003

Jimmy, B., \& Jose, J. (2011) Patient medication adherence: Measures in daily practice. Oman Medical Journal, 26(3), 155-159. http://dx.doi.org/10.5001/omj.2011.38

Jonasson, G., Carlsen, K. H., \& Mowinckel, P. (2000). Asthma drug adherence in a long term clinical trial. Archives of disease in childhood, 83(4), 330-3. http://dx.doi.org/10.1136/adc.83.4.330

Kardas, P., Lewek, P., \& Matyjaszczyk, M. (2013). Determinants of patient adherence: A review of systematic reviews. Front Pharmacol, 4, 91. http://dx.doi.org/10.3389/fphar.2013.00091

Kasper, D. L., Braunwald, E., Fauci, A. S., Hauser, S. L., Longo, D. L., Jameson, J. L., \& Loscalzo, J. (2008). Harrison's principles of internal medicine (17th ed.). New York: McGraw-Hill Medical.

Mardby, A. C., Akerlind, I., \& Jorgensen, T. (2007). Beliefs about medicines and self-reported adherence among pharmacy clients. Patient education and counseling, 69(1), 158-64. http://dx.doi.org/10.1016/ j.pec.2007.08.011

O'Brien, M. K., Petrie, K., \& Raeburn, J. (1992). Adherence to medication regimens: Updating a complex medical issue. Medical care review, 49(4), 435-54. http://dx.doi.org/10.1177/002570879204900403

Polit, D. F., \& Beck, Ch. (2006). Essentials of Nursing Research: Methods, Appraisal, and Utilization (6nd ed.). Philadelphia: Lippincott-Williams \&Wilkins.

Tran, N., Coffman, J. M., Sumino, K., \& Cabana, M. D. (2014). Patient reminder systems and asthma medication $\begin{array}{lllll}\text { adherence: A systematic } & \text { review. } J \text { Asthma., }\end{array}$ http://dx.doi.org/10.3109/02770903.2014.888572.

Schlenk, E. A., Bernardo, L. M., Organist, L. A., Klem, M. L., \& Engberg, S. (2008).Optimizing Medication Adherence in Older Patients: A Systematic Review. Journal of Clinical Outcomes Management, 15(12), 595-606.

Tarantino, V., Cappellari, G., Cardaioli, C., Rumiati, R., Savadori, L., Barilli, E., \& Bisiacchi, P. S. (2010). Sociocognitive factors associated with non-adherence to medication after hospital discharge. Behavioral Medicine, 36(3), 100-7. http://dx.doi.org/10.1080/08964281003774935

To, T., et al. (2012). Global asthma prevalence in adults: Findings from the cross-sectional world health survey. BMC Public Health, 12, 204. http://dx.doi.org/10.1186/1471-2458-12-204

Winer, R. A., Qin, X., Harrington, T., Moorman, J., \& Zahran, H. (2012). Asthma incidence among children and adults: findings from the Behavioral Risk Factor Surveillance system asthma call-back survey-United States, 2006-2008. Journal of Asthma, 49(1), 16-22. http://dx.doi.org/10.3109/02770903.2011.637594

Yang, M. L., Chiang, C. H., Yao, G., \& Wang, K. Y. (2003). Effect of medical education on quality of life in adult asthma patients. Journal of the Formosan Medical Association, 102(11), 768-74.

\section{Copyrights}

Copyright for this article is retained by the author(s), with first publication rights granted to the journal.

This is an open-access article distributed under the terms and conditions of the Creative Commons Attribution license (http://creativecommons.org/licenses/by/3.0/). 